\title{
Development of Minimally Invasive Mid-infrared Lipolysis Laser System for Effective Fat Reduction
}

\author{
Ji-Young Lee \\ Han Young Ryu \\ Young-Seok Seo
}

R\&D Center, Wontech Co., Ltd., Daejeon, Korea

Received March 8, 2021

Accepted March 31, 2021

Correspondence
Ji-Young Lee
R\&D Center Wontech Co., Ltd., 64 techno 8-ro,
Yuseong-gu, Daejeon 34028, Korea
Tel.: +82-70-7841-6526
Fax: +82-70-7863-3350
E-mail: yw106707dawtlaser.com
(C) Korean Society for Laser Medicine and Surgery
@ This is an open access article distributed under the
terms of the Creative Commons Attribution Non-
Commercial License (http://creativecommons.org/
licenses/by-nc/4.0) which permits unrestricted non-
commercial use, distribution, and reproduction in any
medium, provided the original work is properly cited.

\author{
Background and Objectives \\ Due to changes in diet and lifestyle, the number of obese people \\ worldwide is steadily increasing. Obesity has an adverse effect on a \\ healthy life, so it needs treatment and improvement. Research related to \\ this is continuously being conducted.
}

\section{Materials and Methods \\ The laser system to compact designed using $808 \mathrm{~nm}$ laser diode and Neodymium Yttrium orthovanadate generates a $1064 \mathrm{~nm}$ wavelength, the periodically polarized nonlinear crystal pumping laser beam. The pulsed $1064 \mathrm{~nm}$ wavelength beam passing through the $A 0 \mathrm{Q}$-switch is used as the pumping light of the nonlinear optical crystal and is irradiated to the periodic polarized nonlinear optical crystal with a quasi-phase matching period. Nonlinear optical crystals use an oven to control the temperature to generate the desired $1980 \mathrm{~nm}$ and $2300 \mathrm{~nm}$ wavelengths.}

\section{Results}

The $1980 \mathrm{~nm}$ and $2300 \mathrm{~nm}$ wavelengths generated by temperature control of nonlinear optical crystals are effective for lipolysis. A fiber catheter was used so that the laser could be directly irradiated to the fat cells. In particular, the new wavelength (1980 nm, $2300 \mathrm{~nm})$ can increase the fat reduction effect with low energy (1.3 W). When a laser with a combination wavelength of $1980 \mathrm{~nm}$ and $2300 \mathrm{~nm}$ was used, an average lipolysis effect of $20 \%$ was obtained.

\section{Conclusion}

A mid-infrared lipolysis laser system with excellent absorption of fat and water has been developed. We conducted a princlinical study to confirm the efficacy and safety of the lipolysis laser system, and obtained good results for lipolysis with low energy.

\section{Key words}

Mid-infrared; Lipolysis laser; Nonlinear crystal; Preclinical 


\section{INTRODUCTION}

Due to the development of medicine and science, the aging population is increasing as human life span. Due to aging, a lot of time and economic investment led to a healthy life without disease. One of the health-threatening causes is obesity. Obesity is the simple weight of the past means that much of the current obesity is a lot of body fat accumulated in the body, which means a state piled up. Due to changes in eating habits and lifestyles, the number of obese people worldwide is steadily increasing. ${ }^{1}$ Obesity affects health and self-esteem in social activities and medical techniques and devices developed. Laser lipolysis reduces fat and shortens recovery time and works to prevent bleeding by coagulating blood vessels and effective skin tightening by inducing collagen production. ${ }^{2-5}$ This study has developed the world's first minimally invasive lipolysis laser system with 1,980-nm and 2,300-nm wavelengths. The fat reduction by the laser depends on the wavelength and energy of the laser. ${ }^{6}$ Each wavelength used by lipolysis laser has its own characteristics. It has a high hemostatic function, which is a unique role of the 1,064-nm wavelength, and has a high absorption rate of water, so that it also acts as a tightening function. The 1,320-nm wavelength has higher water absorption than $1,064 \mathrm{~nm}$, and has a fat-dissolving effect. The 1,444-nm wavelength is currently the highest fat solubility wavelength used in laser-assisted liposuction (LAL) equipment, which is 40 times higher than 1,064 nm. ${ }^{7}$ As shown in Fig. 1, as the wavelength increases, the absorption of fat and water increase. In general, the subcutaneous fat layer does not contain only fat, but water and fat are mixed together. When the absorption rate for water and fat increases, the solubility of fat is high, increasing the

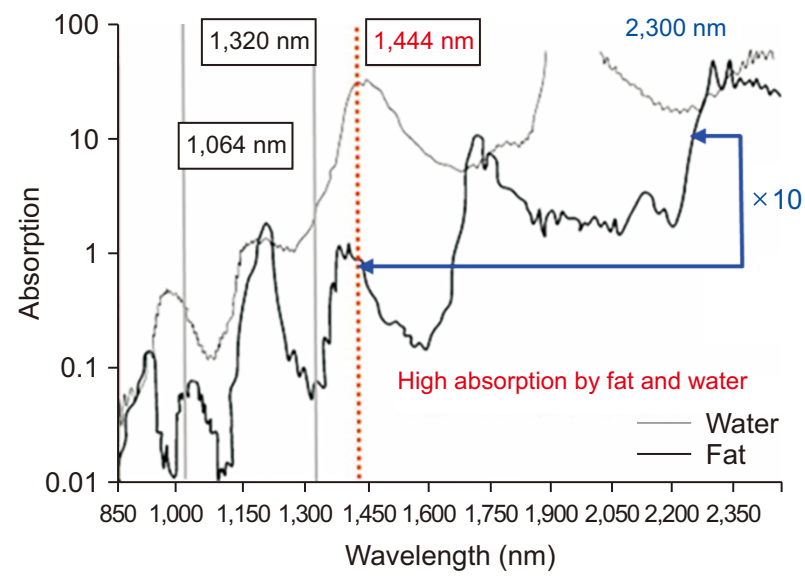

Fig. 1. Comparison of laser absorption rate for fat and water. therapeutic effect. The reason why the 2,000-nm band, which has a higher fat absorption rate at present, is not used because it is technically difficult to generate the desired wavelength and the high absorption of water poses a risk of burns. In this study, 1,980-nm and 2,300-nm laser were developed that are effective for lipolysis. In addition, since it used a lower power (1.3 W) than other wavelength lasers $(1,444 \mathrm{~nm} / 12 \mathrm{~W})$, the risk of burns is reduced.

\section{MATERIALS AND METHODS}

\section{Laser system development}

Generally, neodymium ( $\mathrm{Nd}$ ):yttrium aluminium garnet crystal (YAG) and Nd:Yttrium othovanadate crystal $\left(\mathrm{NO}_{4}\right)$ are used to generate a laser with a wavelength of 1,064$\mathrm{nm}$. Nd:YAG diode pumped solid state (DPSS) laser, ${ }^{8}$ the use of a side-pumping DPSS laser and a Faraday Rotator for polarization control through a polarization element limits the laser head size reduction. To overcome the limitation of size, we designed a modified laser head with a structure using $\mathrm{Nd}: \mathrm{YVO}_{4}$ and 808-nm laser diode (LD). ${ }^{9-11}$ A high power fiber-coupled diode laser pumped the $\mathrm{Nd}: \mathrm{YO}_{4}$ crystal at $808 \mathrm{~nm}$ with a maximum power of $100 \mathrm{~W}$. Nd:YVO 4 has an absorption rate of $808 \mathrm{~nm}$ that is 5 times better than that of $\mathrm{Nd}: Y A G$ and has the same power at a low output than Nd:YAG diode output, thus doubling the lifetime of the diode. It also has the advantage of generating a linear polarized beam of 1,064-nm wavelength. The lens was designed using CodeV to focus the beam diverging from the 808-nm LD onto Nd: $\mathrm{WO}_{4}$. Since Nd:YVO has the characteristic of birefringence, only the beam having the polarization in the direction corresponding to the axial direction can pass. These characteristics affect the output power. As well know, we used a-cut Nd:YVO 4 ( $4 \times 4 \times 20 \mathrm{~mm}, 0.2 \%$ doping) because it has a maximum output power 7 times higher than c-cut. ${ }^{12}$ To keep the $\mathrm{Nd}: \mathrm{YVO}_{4}$ temperature constant, an amount including a cooling system was designed. An acousto optical (AO) Qswitch was used to make a pulse beam. AO Q-switch was intended to have a pulse repetition rate of several $\mathrm{kHz}$ using crystal quartz. ${ }^{13}$ A pulsed 1,064-nm wavelength beam is used as a pumping beam for the opticla parametric oscillators (OPO) cavity. The OPO cavity consists of a periodically polarized nonlinear optical crystal with a quasi phasematching (QPM) period and a back mirror, and an out mirror. To obtain a wavelength of $2 \mu \mathrm{m}$ suitable for lipolysis, periodically poled stoichiometric lithium tantalate (PPSLT) crystal (3 $\times 3 \times 20$ mm, $32.19 \mu \mathrm{m}$ grating period) was selected as shown in Fig. 2. by calculating the wavelength change with the temperature of the nonlinear opti- 
cal crystal. ${ }^{14-17}$

We used the depend on temperature Sellmeier equation for the extraordinary refractive index of stoichiometric lithium tantalate crystal (SLT) proposed by Bruner. ${ }^{18,19}$ All of the OPO cavity mirrors were flat mirrors. The back

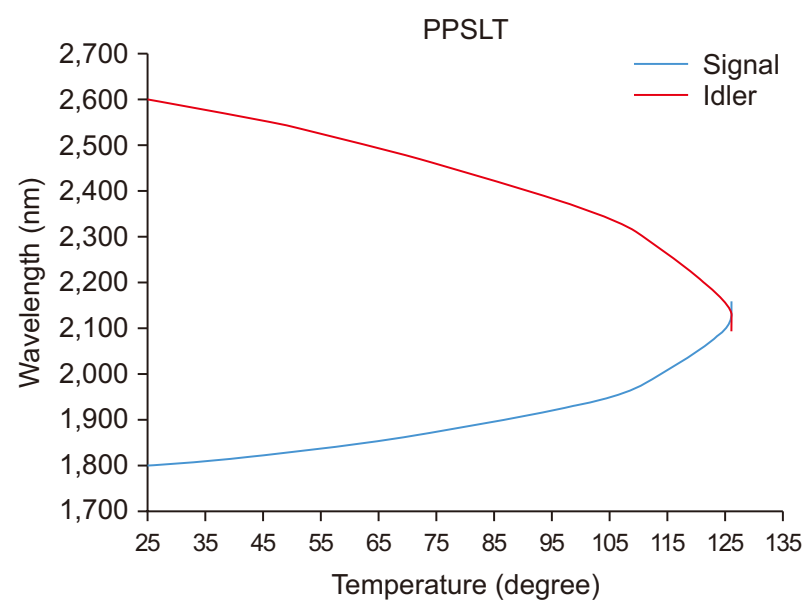

Fig. 2. Wavelengths variation of nonlinear optical crystal with temperature. PPSLT, periodically poled stoichiometric lithium tantalate. mirror is highly transmitting ( $T>95 \%)$ for the pump beam and highly reflective ( $P>97 \%)$ for the $2 \mu$ m wavelengths. Out mirror is highly reflective ( $\mathrm{R}>99 \%)$ for the pump beam and partial transmitting ( $\mathrm{T}>50 \%$ ) for the $2 \mu \mathrm{m}$ wavelengths. To control nonlinear optical crystal temperature to obtain a stable wavelength with heater oven using real-time temperature sensor was made. When the pumping beam of 1,064 $\mathrm{nm}$ is incident on the nonlinear optical crystal, the second harmonic of $532 \mathrm{~nm}$ wavelength is generated. ${ }^{20}$ It generated the crystal temperature changes, mid-infrared of 1,980-nm and 2,300$\mathrm{nm}$ wavelengths. The result of the wavelength change calculation according to the nonlinear optical crystal temperature was $110^{\circ} \mathrm{C}$. We designed and fabricated an oven to control nonlinear optical crystal temperature, as shown in Fig. 3.

A beam of $1,064 \mathrm{~nm}$ is pumped into the nonlinear optical crystal, and the second harmonic of 532-nm wavelength is generated. The wavelengths generation from increasing the temperature of the oven were measured. As a result, we have achieved wavelengths of 1,980 nm and $2,300 \mathrm{~nm}$ at $175^{\circ} \mathrm{C}$. We have a set of nonlinear optical crystal temperatures of about $175^{\circ} \mathrm{C}$ according to the


Fig. 4. Output wavelength and power measurement results of the lipolysis laser system.
Fig. 3. Oven for temperature control of nonlinear optical crystal, (A) design, (B) production and application. 


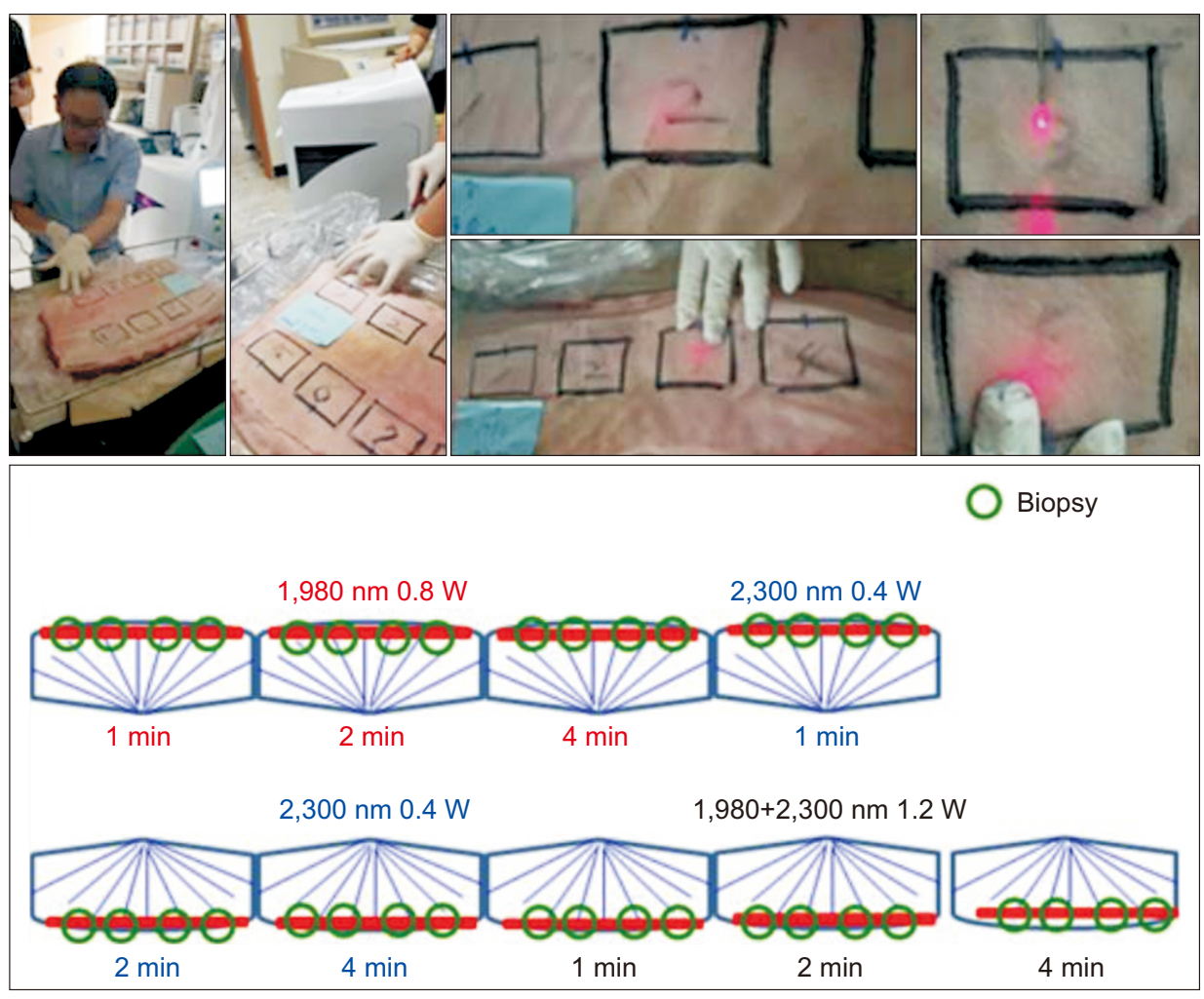

Fig. 5. Design of mid-infrared lipolysis laser in the ex-vivo experiment. experimental results.

As shown in Fig. 4, 532-nm second harmonic generation beam is reflected by the folding mirror, $1,980 \mathrm{~nm}$ and 2,300 $\mathrm{nm}$ are passed through the selection filter. We designed a coupling lens to focus at 1,980-nm and 2,300$\mathrm{nm}$ wavelengths on the fiber. We developed a lipolysis laser system with 1,980-nm and 2,300-nm wavelengths included with laser head, temperature controller, power supply, and cooling system.

\section{RESULTS}

\section{Lipolysis preclinical experiment results and dis- cussion}

We conducted preclinical ex-vivo and in-vivo to confirm the minimally invasive mid-infrared lipolysis laser safety and efficacy.

\section{Ex-vivo experiment}

First, ex-vivo experiments were performed to determine the power of wavelengths of $1,980 \mathrm{~nm}$ and $2,300 \mathrm{~nm} .{ }^{21}$ It was designed and experimented as shown in Fig. 5. using pig bulk tissue. A cannula is used to deliver the laser irradiated from the fiber tip to the adipose tissue. To confirm reducing the fat cells by laser without damage by the cannula and tissue changes in the red line area were
Table 1. Conditions of mid-infrared lipolysis laser irradiation in the ex-vivo experiment

\begin{tabular}{lcc}
\hline \multicolumn{1}{c}{ Wavelength } & Power & Time \\
\hline $1,980 \mathrm{~nm}$ & $0.8 \mathrm{~W}$ & $1 \mathrm{~min}, 2 \mathrm{~min}, 4 \mathrm{~min}$ \\
$2,300 \mathrm{~nm}$ & $0.4 \mathrm{~W}$ & $1 \mathrm{~min}, 2 \mathrm{~min}, 4 \mathrm{~min}$ \\
$1,980 \mathrm{~nm}+2,300 \mathrm{~nm}$ & $1.2 \mathrm{~W}$ & $1 \mathrm{~min}, 2 \mathrm{~min}, 4 \mathrm{~min}$ \\
\hline
\end{tabular}

observed. Laser irradiation condition, as shown in Table 1.

The guide beam was used to visually check where the laser was irradiated. After laser irradiation, a tissue sample was extracted and histological analysis was performed.

After laser irradiation, hematoxylin \& eosin (H\&E) staining was used to analyze changes in adipose tissue. As shown in Fig. 6, in the case of irradiation for 4 minutes with a combination of 1,980 $\mathrm{nm}$ and 2,300 $\mathrm{nm}$, fat cells decomposed.

\section{In-vivo experiment}

Based on the results of the ex-vivo experiment, in vivo animal experiment was performed. IRB approval was obtained for this experiment. In the experiment design, the abdomen of a 12 months old male mini-pig was divided into six parts and irradiated with a laser. Skin color, hair follicles, sweat glands, and subcutaneous fat were 


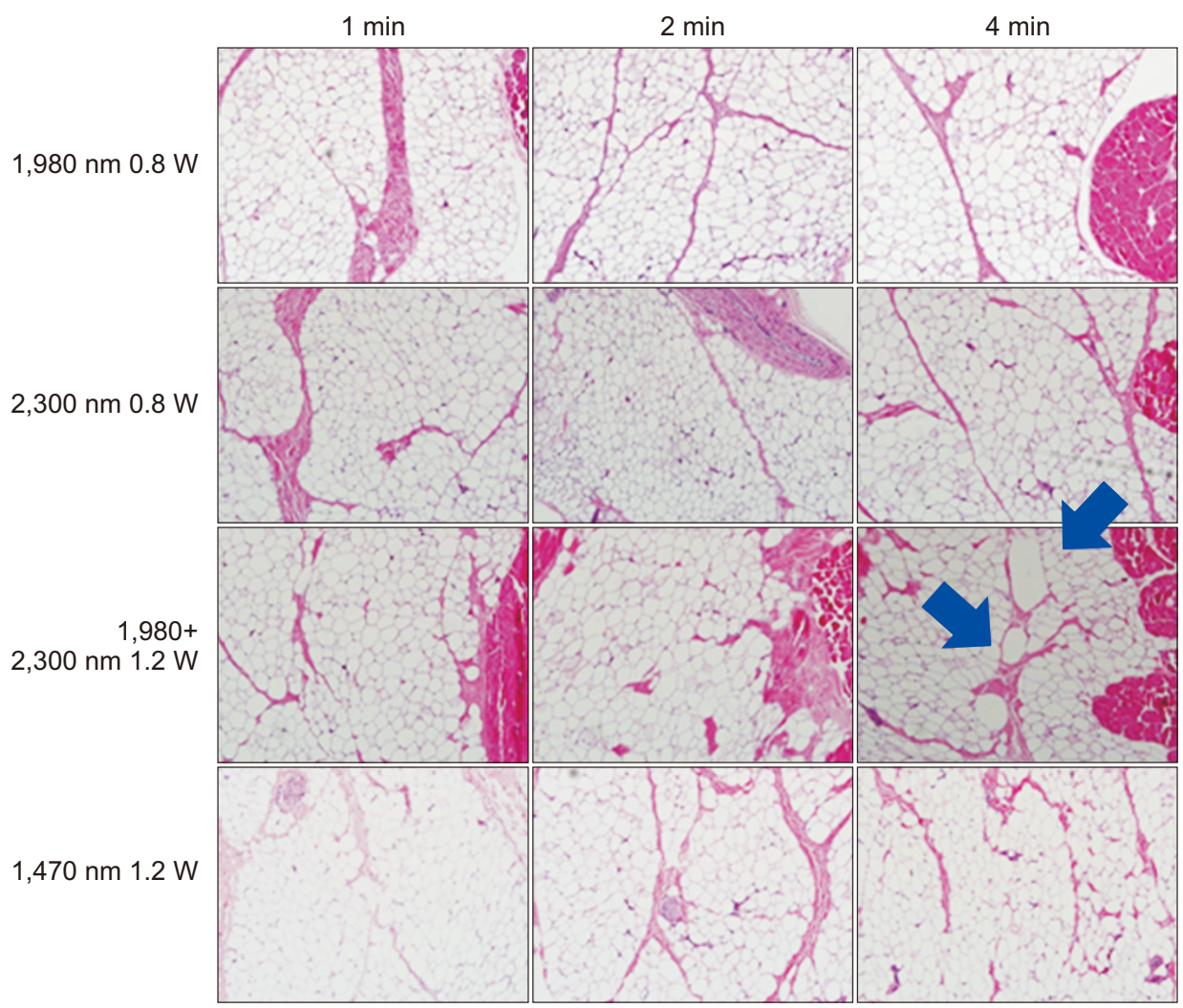

Fig. 6. Hematoxylin \& eosin (H\&E) staining results after the ex-vivo experiment (original magnification, $\times 100$ ).
Table 2. Conditions of mid-infrared lipolysis laser irradiation in the in-vivo experiment

\begin{tabular}{llcc}
\hline \multicolumn{1}{c}{ Part\# } & \multicolumn{1}{c}{ Wavelength } & Power & Time \\
\hline $1 \sim 5$ (Experimental Group) & $1,980 \mathrm{~nm}+2,300 \mathrm{~nm}$ & $1.2 \mathrm{~W}$ & $5 \mathrm{~min}$ \\
6 (Control) & $1,470 \mathrm{~nm}$ & $1.2 \mathrm{~W}$ & $5 \mathrm{~min}$ \\
\hline
\end{tabular}

experimented with using mini pigs similar to humans. ${ }^{22,23}$ Pig skin, similar to humans, has relatively few coats, and the subcutaneous tissue is firmly connected. The overall shape of epidermal thickness, cellular composition, and cutaneous blood supply is similar to that of humans, expect that there is no apocrine sweat gland. The laser irradiation conditions are as shown in Table 2 .

After laser irradiation, safety was confirmed through blood tests and visual observation of skin and biopsy. To check the efficacy and the change in the thickness of the fat layer was measured using ultrasound. Visual observation of skin was performed before and at $0,1,7,15,30$, 60, 90 days after laser irradiation. As shown in Fig. 7, the abnormal change due to the laser irradiation confirmed could not be.

To confirm physiology safety, H\&E staining of the tissue was performed 15, 30, 60, and 90 days after laser irradiation. As a result, it was observed that other cytoplasm, muscle cells and intracytoplasmic fibrous tissue were formed in the deformed part of the adipose tissue. As a result of observation, as shown in Fig. 8, after 30 days, other cytoplasm, muscle cells and intracytoplasmic fibrous tissue were generated in all areas, but \#6 (control) was relatively lower than that of other elements lexperimental group).

During 3 days after laser irradiation, a total of 8 blood tests $(0,2,4,8,12,18,24,48,72$ hours) were performed to confirm changes in liver function, kidney function, and lipid levels. As shown in Table 3, the aspartate transaminase (AST) level showed a tendency to increase between 4 and 24 hours of laser irradiation but returned to normal after 48 hours.

To confirm the efficacy and changes in the fat layer's thickness were measured by abdominal ultrasound before and immediately, 1, 7, 15, 30, 60, 90 days after laser irradiation. Fig. 9 showns the ultrasound measured before and 90 days after laser irradiation in \#1. The thickness of the fat layer decreased by $33 \%$ from $7.22 \mathrm{~mm}$ before laser irradiation to $4.86 \mathrm{~mm}$ after 90 days of laser irradiation. As shown in Fig. 10 of measurement results, found that the thickness of the fat layer increased in all areas after 1 day of irradiation. It can see that it increases by more than $40 \%$ in $\# 1$ and decreases rapidly after 7 days. 


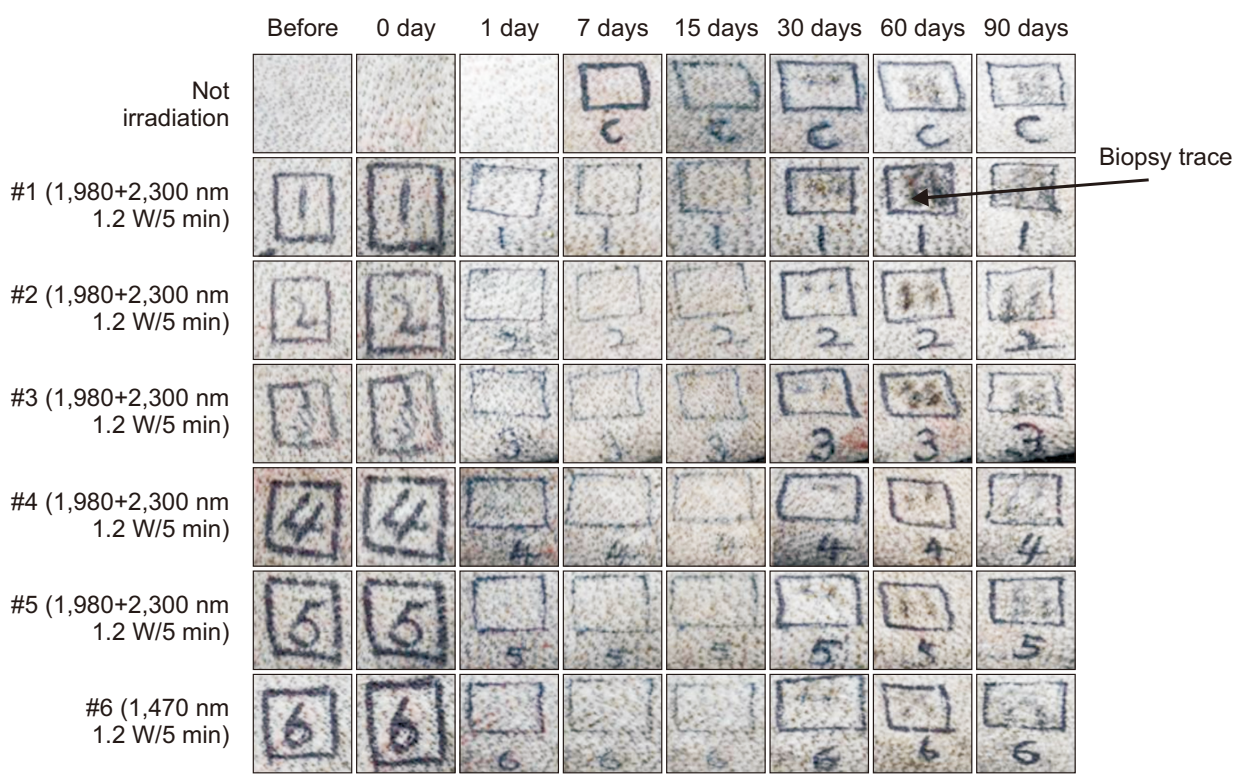

Fig. 7. Visual observation for 90 days before and after laser irradiation.

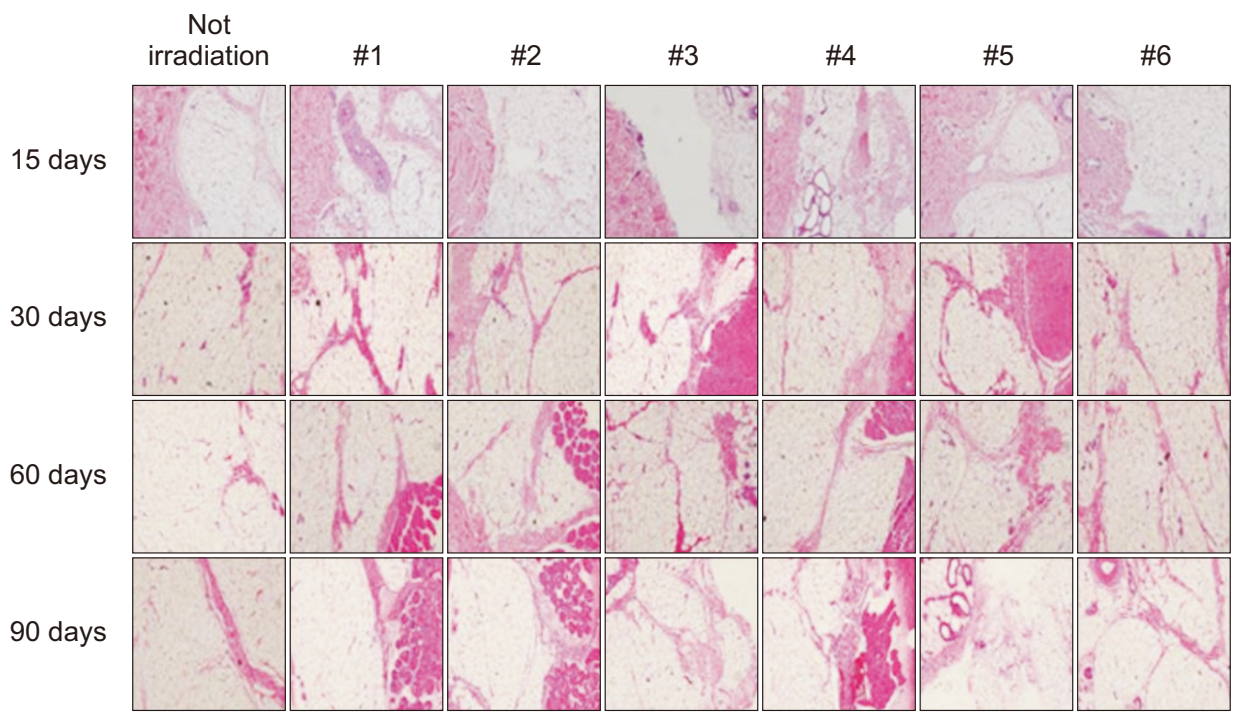

Fig. 8. H\&E staining results after laser irradiation (original magnification, $\times 100)$.

Table 3. Blood test results after laser irradiation

\begin{tabular}{|c|c|c|c|c|c|c|c|c|c|c|c|c|c|c|c|c|c|}
\hline Item & TP & ALB & GLB & $A / G$ & AST & ALT & BUN & T-BIL & T-CHO & ALP & $\mathrm{Ca}$ & $P$ & TG & CREA & HDL-C & LDL-C & NEFA \\
\hline Unit & $\mathrm{g} / \mathrm{dL}$ & $\mathrm{g} / \mathrm{dL}$ & $\mathrm{g} / \mathrm{dL}$ & Ratio & IU/L & $\mathrm{IU} / \mathrm{L}$ & $\mathrm{mg} / \mathrm{dL}$ & $\mathrm{mg} / \mathrm{dL}$ & $\mathrm{mg} / \mathrm{dL}$ & IU/L & $\mathrm{mg} / \mathrm{dL}$ & $\mathrm{mg} / \mathrm{dL}$ & $\mathrm{mg} / \mathrm{dL}$ & $\mathrm{mg} / \mathrm{dL}$ & $\mathrm{mg} / \mathrm{dL}$ & $\mathrm{mg} / \mathrm{dL}$ & $\mathrm{mEq} / \mathrm{L}$ \\
\hline $\mathrm{D} 9-150 \mathrm{H}$ & 7.1 & 41 & 3.0 & 1.4 & 47 & 42 & 10.4 & 0.00 & 88 & 73 & 11.1 & 6.9 & 23 & 2.27 & 40.9 & 38.9 & 147 \\
\hline D9-152H & 6.7 & 3.9 & 2.8 & 1.4 & 51 & 39 & 10.6 & 0.02 & 83 & 75 & 10.6 & 6.4 & 17 & 2.27 & 37.9 & 38.3 & 113 \\
\hline D9-154H & 8.1 & 4.6 & 3.5 & 1.3 & 102 & 46 & 14.3 & 0.05 & 96 & 84 & 11.8 & 7.4 & 20 & 2.54 & 44.3 & 43.4 & 191 \\
\hline D9-158H & 7.9 & 4.6 & 3.3 & 1.4 & 160 & 48 & 17.8 & 0.06 & 90 & 85 & 11.4 & 7.9 & 19 & 2.53 & 41.7 & 42.1 & 198 \\
\hline D9-15 12H & 7.5 & 4.4 & 3.1 & 1.4 & 269 & 48 & 22.2 & 0.09 & 84 & 86 & 10.8 & 8.2 & 17 & 2.53 & 37.1 & 40.9 & 198 \\
\hline D9-15 24H & 7.3 & 4.2 & 3.1 & 1.4 & 90 & 43 & 19.8 & 0.02 & 79 & 76 & 10.2 & 5.4 & 17 & 2.22 & 38.0 & 35.9 & 80 \\
\hline D9-1548H & 8.3 & 4.7 & 3.6 & 1.3 & 57 & 52 & 12.4 & 0.03 & 101 & 81 & 10.9 & 6.3 & 21 & 2.21 & 48.7 & 43.7 & 141 \\
\hline D9-15 72H & 7.8 & 4.5 & 3.3 & 1.4 & 42 & 52 & 13.1 & 0.02 & 115 & 86 & 11.7 & 5.9 & 40 & 2.22 & 51.1 & 50.3 & 36 \\
\hline Mean & 7.6 & 4.4 & 3.2 & 1.4 & 102 & 46 & 15.1 & 0.04 & 92 & 81 & 11.1 & 6.8 & 22 & 2.35 & 42.5 & 41.7 & 138 \\
\hline SD & 0.5 & 0.3 & 0.3 & 0.0 & 78 & 5 & 4.4 & 0.03 & 12 & 5 & 0.6 & 1.0 & 8 & 0.15 & 5.2 & 4.4 & 59 \\
\hline $\mathrm{N}$ & 8.0 & 8.0 & 8.0 & 8.0 & 8 & 8 & 8.0 & 8.00 & 8 & 8 & 8.0 & 8.0 & 8 & 8.00 & 8.0 & 8.0 & 8 \\
\hline
\end{tabular}

D, day; H, hour; SD, standard deviation; TP, total protein; ALB, albumin; GLB, globulin; A/G, albumin/globulin ratio; AST, aspartate transaminase; ALT, alanine aminotransferase; BUN, blood urea nitrogen; T-BIL, total bilirubin; T-CHO, total cholesterol; ALP, alkaline phosphatase; TG, triglyceride; CREA, creatinine; HDL-C, high density lipoprotein cholesterol; LDL-C, low density lipoprotein cholesterol; NEFA, non-esterified fatty acid. 

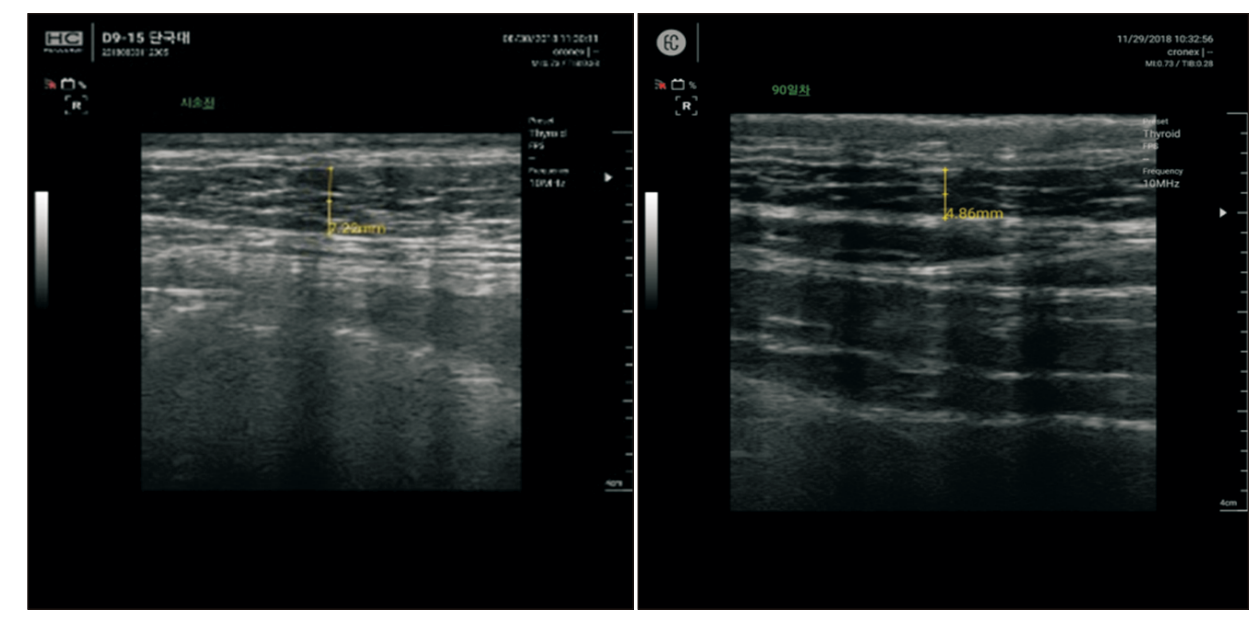

Fig. 9. Ultrasound results measured before and 90 days after laser irradiation in \#1.



Fig. 10. Fat layer thickness change graph after laser irradiation.

The fat thickness of all parts decreased by 30 days and increased by $5 \%$ at \#4, \#5, \#6 at 60 days. For 90 days after laser irradiation was the thickness, the difference depending on location decreased $5-35 \%$ of all parts. When the combination wavelength of $1,980 \mathrm{~nm}$ and $2,300 \mathrm{~nm}$ was irradiated (\#1-\#5), there was a tendency to decrease continuously after 60 days. However, when irradiated with a wavelength of $1,470 \mathrm{~nm}(\# 6)$, there is no tendency to fall.

\section{DISCUSSION}

We developed a minimally invasive lipolysis laser system that uses the nonlinear optical crystal to produce wavelengths of 1,980 $\mathrm{nm}$ and 2,300 $\mathrm{nm}$ with good absorption of water and fat. A preclinical study was conducted in mini pig to confirm the minimally invasive lipolysis laser safety and efficacy. When irradiated with a combination of 1,980-nm and 2,300-nm wavelengths has obtained an average of $20 \%$ fat reduction. Blood tests and biopsies have confirmed the minimally invasive mid-infrared lipolysis laser system to be safe.

Based on the results of animal experiments, the minimally invasive mid-infrared lipolysis laser system was the first clinical trial with the approval of the clinical protocol of The Ministry of Food and Drug Safety (MFDS). Currently, the clinical trial is finished, and statistical processing is in progress.

\section{CONFLICT OF INTEREST}

No potential conflict of interest relevant to this article was reported.

\section{FUNDING}

It was carried out with support from Establishment of joint research corporation and operation support industry of Korea Innovation Foundation.

\section{REFERENCES}

1. Khan A, Choudhury N, Uddin S, Hossain L, Baur LA. Longitudinal trends in global obesity research and collaboration: a review using bibliometric metadata. Obes Rev 2016;17:377-85.

2. Lukac M, Vizintin Z, Zabkar J, Pirnat S. QCW pulsed Nd:YAG 1064 nm laser lipolysis. J Laser Health Acad 2009;2009:86493.

3. Badin AZ, Moraes LM, Gondek L, Chiaratti MG, Canta L. Laser lipolysis: flaccidity under control. Aesthetic Plast Surg 2002;26:335-9

4. O'Dey Dm, Prescher A, Poprawe R, Gaus S, Stanzel S, Pallua N. Ablative targeting of fatty-tissue using a high-powered diode laser. Lasers Surg Med 2008;40:100-5.

5. Nestor MS, Newburger J, Zarraga MB. Body contouring using 635-nm low level laser therapy. Semin Cutan Med Surg 2013;32:35-40. 
6. Goldman A, Schavelzon DE, Blugerman GS. Laserlipolysis: liposuction using Nd-YAG laser. Rev Soc Bras Cir Plást 2002;17:17-21.

7. McBean JC, Katz BE. Laser lipolysis: an update. J Clin Aesthet Dermatol 2011;4:25-34.

8. Kim B, Kim DY. Enhanced tissue ablation efficiency with a midinfrared nonlinear frequency conversion laser system and tissue interaction monitoring using optical coherence tomography. Sensors (Basel) 2016;16:598.

9. Délen X, Balembois F, Musset O, Georges P. Characteristics of laser operation at $1064 \mathrm{~nm}$ in Nd:YV04 under diode pumping at 808 and 914 nm. J Opt Soc Am B 2011;28:52-7.

10. Zhuo Z, Li T, Li X, Yang H. Investigation of $\mathrm{Nd}: \mathrm{YO}_{4} / \mathrm{NO}_{4}$ composite crystal and its laser performance pumped by a fiber coupled diode laser. Opt Commun 2007;274:176-81.

11. Chen YF. cw dual-wavelength operation of a diode-endpumped Nd:YVO laser. Appl Phys B 2000;70:475-8.

12. Chen YF, Lan YP. Comparison between $c$-cut and a-cut $\mathrm{Nd}: \mathrm{YO}_{4}$ lasers passively $\mathrm{Q}$-switched with a $\mathrm{Cr}^{4}+\mathrm{YAG}$ saturable absorber. Appl Phys B 2002; 74:415-8.

13. Choo HT, Kim GU, Park CG, Choi JH, Rhyee KH. Laser-diodepumped passively Q-switched Nd:YVO4 self-raman laser at 1178 nm. NPSM 2016;66:647-53.

14. Myers LE, Eckardt RC, Fejer MM, Byer RL, Bosenberg WR, Pierce JW. Quasi-phase-matched optical parametric oscillators in bulk periodically poled $\mathrm{LiNbO}_{3}$. J Opt Soc Am B 1995;12:2102-16.

15. Duan Y, Zhu H, Xu C, Ruan X, Cui G, Zhang Y, et al. Compact self-cascaded KTA-OPO for $2.6 \mu \mathrm{m}$ laser generation. Opt Express 2016;24:26529-35.

16. Kumar SC, Ebrahim-Zadeh M. High-power, fiber-laser- pumped, picosecond optical parametric oscillator based on MgO:sPPLT. Opt Express 2011;19:26660-5.

17. Peltola J, Vainio M, Hieta T, Uotila J, Sinisalo S, Metsälä M, et al. High sensitivity trace gas detection by cantilever-enhanced photoacoustic spectroscopy using a mid-infrared continuouswave optical parametric oscillator. Opt Express 2013;21:1024050.

18. Bruner A, Eger D, Oron MB, Blau P, Katz M, Ruschin S. Temperature-dependent Sellmeier equation for the refractive index of stoichiometric lithium tantalate. Opt Lett 2003;28:194-6.

19. Wen-Le W, You-Wen L, Xiao-Qi Z. Temperature-dependent Sellmeier equation for $1.0 \mathrm{~mol} \% \mathrm{Mg}$-doped stoichiometric lithium tantalate. Chin Phys Lett 2008;25:4303-6.

20. Pati B, Wall KF, Moulton PF. High-efficiency 532-nm generation with PPSLT. Advanced Solid State Photonics; 2010 Jan 31 Feb 3; San Diego. OSA Publishing; 2010. p. ATuA17.

21. Kim B, Kim DY. Enhanced tissue ablation efficiency with a midinfrared nonlinear frequency conversion laser system and tissue interaction monitoring using optical coherence tomography. Sensors (Basel) 2016;16:598.

22. Yeom SC. Miniature pig as laboratory animal. J Korean Vet Med Assoc 2011;47:142-55.

23. Zhang Z, Monteiro-Riviere NA. Comparison of integrins in human skin, pig skin, and perfused skin: an in vitro skin toxicology model. J Appl Toxicol 1997;17:247-53.

How to cite this article: Lee JY, Ryu HY, Seo YS. Development of minimally invasive mid-infrared lipolysis laser system for effective fat reduction. Med Lasers 2021;10:82-89. https:// doi.org/10.25289/ML.2021.10.2.82 